\title{
DESAFIOS NA PRODUÇÃO DO CONHECIMENTO EM BIOTECNOLOGIA
}

\author{
Oliveira, $\mathrm{MM}^{*}$, Souza Neto ${ }^{* *}$, Granjeiro $\mathrm{PA}^{* * *}$
}

\section{Resumo}

Um obstáculo para o Brasil ser reconhecido mundialmente por suas pesquisas em biotecnologia está na burocracia de processos para a aprovação de solicitações, incluindo autorizações de comitês de ética em pesquisa envolvendo seres humanos e animais, o acesso ao patrimônio genético nacional, autorizações estaduais e os pedidos de patentes. O objetivo deste trabalho foi apresentar fluxogramas dos trâmites de acesso às solicitações nas áreas biológicas e afins e as documentações exigidas em cada caso, de modo a servir como fonte de consulta para os pesquisadores na prática. Em razão do excesso de formulários, prazos, entre outras documentações regulamentares, existem resultados desfavoráveis relacionados à produção nacional científica, incluindo a produção de patentes nacionais. Embora a regularização governamental sobre o envolvimento de seres humanos e animais em pesquisas, o acesso ao patrimônio genético e o pedido de patentes sejam essenciais para a preservação da biodiversidade do país, a prevenção de danos e o respeito à propriedade, existem alguns entraves que geram reflexos negativos no crescimento científico nacional.

Palavras-chave: Produção do conhecimento. Biotecnologia. Entraves burocráticos.

\footnotetext{
* Mestre em Gestão Integrada do Território pela Vale do Rio Doce; Graduada em Psicologia pela Universidade Vale do Rio Doce; Professora mestre na Faculdade de Mantena; Rua Israel Pinheiro, 2000 Universitário, 35020-220, Governador Valadares, Minas Gerais, Brasil; marinamendesufsj@gmail.com

** Doutor e Mestre em Engenharia de Produção pela Universidade Federal do Rio de Janeiro com ênfase em Empreendedorismo à brasileira e Educação Empreendedora; Professor Associado do Departamento de Ciências Administrativas e Contábeis da Universidade Federal de São João del-Rei; bezamat@ufsj.edu.br

${ }^{* * *}$ Doutor e Mestre em Biologia Funcional e Molecular na área de Bioquímica pela Universidade Estadual de Campinas; Professor Adjunto IV do Campus Centro-Oeste Dona Lindu da Universidade Federal de São João del-Rei; pagranjeiro@gmail.com
} 


\title{
Challenges in the production of knowledge in biotechnology
}

\begin{abstract}
An obstacle for Brazil to be recognized worldwide for its researches in biotechnology is in the bureaucracy of the process for the approval of licenses, including the ethical committee authorizations in researches evolving humans and animals, the access to the genetic national patrimony, state authorizations and the patent requests. The objective of this study was to present flowcharts showing the forms to access the solicitations in the area of biology and similar, as the documents demanded in each case, serving as for consultation source for researchers who need to obtain these authorizations. Due to the excess of forms, expiration dates, among other regulatory documents, there are unfavorable results related to the national scientific production, including the valid national patent rate. Although the national regularization on the involvement of humans and animals in researches, the access to the genetic patrimony and order of patents are essential for the preservation of the country's biodiversity, the prevention of damages and the respect for the legislation, there are some barriers that create negative reflexes in the scientific growth of the country.
\end{abstract}

Keywords: Production of knowledge. Biotechnology. Bureaucracy barriers.

\section{INTRODUÇÃO}

As pesquisas em biotecnologia dispõem de um grande potencial inovador diante da biodiversidade do Brasil, com destaque para a fauna e a flora potencialmente produtivas que ampliam os recursos genéticos para pesquisas. Entretanto, as pesquisas biotecnológicas no Brasil ainda não apresentaram indicadores significativos no que se refere à incorporação desses conhecimentos em produtos e processos em escala industrial. ${ }^{1}$

Nesse contexto, muitas são as vertentes passíveis a serem analisadas ao discutir os desafios na prática de desenvolver pesquisas no Brasil. Pode-se enxergar alguns entraves burocráticos nas aprovações do Comitê de Ética em Pesquisa (CEP) envolvendo seres humanos e nas pesquisas com uso de animais, por meio do Conselho Nacional de Controle de Experimentação Animal (Concea), no acesso ao patrimônio genético (PG) e ao Conhecimento Tradicional Associado (CTA) por meio do Conselho de Gestão do Patrimônio Genético (Cgen), no acesso à coleta de material em reserva ambiental pelo Instituto Estadual de Florestas (IEF - Minas Gerais) e na solicitação de patentes pelo Instituto Nacional de Propriedade Industrial (INPI). Na Figura 1 apresentam-se as principais licenças relacionadas às pesquisas em biotecnologia. 
Figura 1 - Principais solicitações relacionadas às pesquisas em biotecnologia

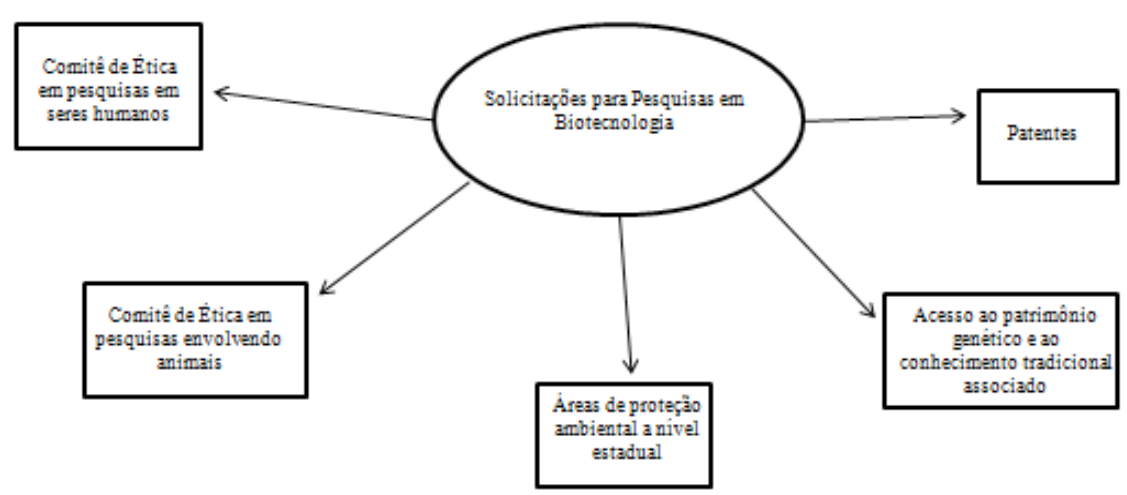

Fonte: os autores.

De acordo com Frasca, ${ }^{2}$ a morosidade no processo de aprovação das pesquisas pode interferir no número de medicamentos lançados no mercado brasileiro a cada ano, pois muitos novos estudos são barrados pela burocracia no Brasil.

A proposta deste trabalho foram disponibilizar informações que possam servir de fonte de consulta aos trâmites processuais para os temas relacionados às pesquisas que envolvam seres humanos, animais, acesso ao patrimônio genético e ao conhecimento tradicional associado, além do acesso à coleta de material biológico regulamentado pelo Instituto Estadual de Florestas (IEF-MG) e ao registro de patentes.

\section{MÉTODOS}

A proposta dos fluxogramas foi de indicar o passo a passo, muitas vezes longo e burocrático, para concluir as solicitações relacionadas à produção do conhecimento nas áreas biológicas e afins com enfoque na biotecnologia.

Mesmo considerando que os fluxogramas de solicitação de acesso em todas as entidades administrativas podem sofrer alterações, este trabalho propôs exemplificar de forma pioneira os inúmeros procedimentos exigidos.

Utilizou-se uma margem de tempo elevada diante do próprio contexto burocrático do problema. Entretanto, o levantamento da documentação necessária para as licenças na área biotecnológica foi mais atual ao ser consultado por meio dos sites oficiais de cada órgão governamental.

\section{RESULTADOS}

\subsection{PESQUISAS ENVOLVENDO SERES HUMANOS}

A Plataforma Brasil ${ }^{3}$ é um sistema eletrônico criado pelo Governo Federal para sistematizar o recebimento dos projetos de pesquisa que envolvam seres humanos nos Comitês de Ética em todo o 
território brasileiro. Nessa Plataforma, o pesquisador tramita de modo on-line os documentos para a solicitação da autorização para realizar sua pesquisa envolvendo seres humanos, visto que a plataforma direciona a solicitação ao CEP da instituição do pesquisador e à Comissão Nacional de Ética e Pesquisa (Conep), quando necessário. Essa plataforma permite que as pesquisas sejam acompanhadas em seus diferentes estágios, desde sua submissão até a aprovação final pelo CEP, possibilitando, inclusive, o acompanhamento da fase de campo e o envio de relatórios parciais e finais das pesquisas.

Em um primeiro momento, o pesquisador deverá preencher os dados de seu cadastro pessoal e da instituição para depois submeter à pesquisa pretendida, como também deverá ser encaminhada a folha de rosto digitalizada com a assinatura do pesquisador coordenador e do responsável pela instituição proponente.

Mais especificamente, as pesquisas que envolvem seres humanos podem ser divididas em genética humana, novos fármacos e reprodução humana, entre outras. Para cada grupo, existem documentos específicos que devem ser enviados.

Dessa forma, em linhas gerais, o fluxograma inicial da aprovação do Comitê de Ética ${ }^{4}$ em Pesquisa envolvendo seres humanos acontece seguindo o Fluxograma apresentado na Figura 2.

Figura 2 - Fluxograma de aprovação do Comitê de Ética em Pesquisa

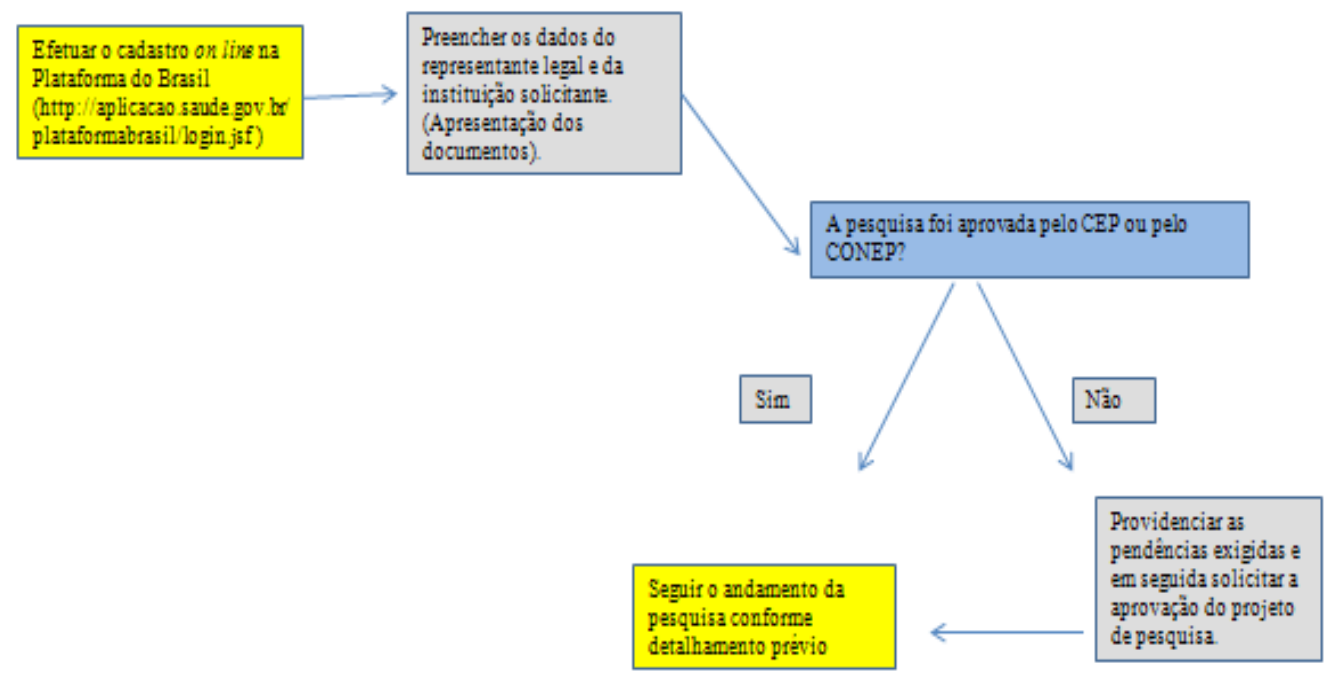

Fonte: adaptada de Brasil. ${ }^{4}$

\subsection{PESQUISA ENVOLVENDO O USO DE ANIMAIS}

As instituições que necessitam se cadastrar no Conselho Nacional de Controle de Experimentação Animal (Concea) e com isso conseguir o credenciamento institucional deverão efetuar o cadastro on-line diretamente no site do Concea. Em um primeiro momento, deverá ser efetuado o cadastro de novo acesso e, em seguida, o CNPJ e o endereço eletrônico do responsável legal deverão ser informados. ${ }^{5}$ 
Ao entrar no sistema, após efetuar o cadastro, o sistema disponibilizará quatro telas identificadas com: Cadastro, Anexo, Visualizar Formulário, Submeter ao Concea e Fale Conosco. O representante legal deverá, em seguida, incluir informações acerca do Setor da Atividade Econômica no qual a instituição está inserida, como, por exemplo, saúde humana e serviços sociais, educação, agricultura, entre outros. ${ }^{6}$

Do mesmo modo, a instituição deverá apresentar o Alvará de Funcionamento, o Currículo Lattes do responsável pela criação do biotério, o Currículo Lattes dos membros do Conselho de Ética para Uso de Animais (CEUA), o ato de nomeação do CEUA e o formulário utilizado pelo CEUA para o registro de informações dos protocolos de ensino e pesquisa para que o credenciamento possa ser efetuado. Após esses trâmites, as instituições necessitarão, ainda, cadastrar cada novo projeto que utilizará os animais contidos no biotério da instituição.

Entretanto, é importante reforçar que, para requerer o credenciamento para utilizar animais para fins de pesquisa, a instituição deverá possuir previamente um Conselho de Ética no Uso de Animais (CEUA) próprio. ${ }^{4}$

A criação de um Conselho de Ética no Uso de Animais (CEUA) próprio deve obedecer às exigências da Orientação Técnica n. 3, de outubro de 2013, que preconiza que as instituições, a fim de solicitar o Credenciamento Institucional para Atividades com Animais em Ensino ou Pesquisa (Ciaep), devem comprovar os meios pelos quais o CEUA foi criado, por meio dos seguintes documentos: ${ }^{7}$

a) ato de criação do CEUA, assinado pelo representante legal da instituição;

b) ato de nomeação dos seus membros titulares e respectivos suplentes, assinado pelo representante legal da instituição, contendo o período dos respectivos mandatos;

c) links dos Currículos Lattes de todos os membros do CEUA.

Os membros que compõem o CEUA também deverão ser informados de forma atualizada; o Conselho deverá conter pelo menos cinco membros titulares e seus respectivos suplentes, sendo obrigatória a participação de um médico veterinário titular, um biólogo titular e um representante de Sociedade Protetora de Animais (SPA), legalmente constituída e estabelecida no país. Todavia, a legislação permite a contratação de especialista ad hoc com comprovada experiência em uso ético de animais para compor os representantes de um CEUA institucional. ${ }^{7}$

A fim de se conseguir o Credenciamento Institucional para Atividades com Animais em Ensino ou Pesquisa (Ciaep), o biotério deve ter sido previamente cadastrado pela instituição no mesmo sistema do Cadastro das Instituições de Uso Científico de Animais (CIUCA). Para cadastrar o biotério, deverão ser fornecidas informações acerca da infraestrutura do local onde os animais serão colocados com a devida comprovação da planta baixa, em forma de anexo, associadas aos nomes e ao Currículo Lattes do coordenador do biotério e do responsável técnico., ${ }^{4,6}$

Portanto, a submissão de pesquisas que envolvem o uso de animais acontece de modo online via Plataforma CIUCA. Os prazos, nesse caso, dependem da própria instituição na apresentação 
dos documentos e da entrega dos pré-requisitos requeridos, como a construção de um Conselho de Ética no Uso de Animais vigente e um biotério cadastrado no CEUA. Os trâmites processuais estão demonstrados no Fluxograma da Figura 3.

Figura 3 - Fluxograma de Aprovação do CEUA

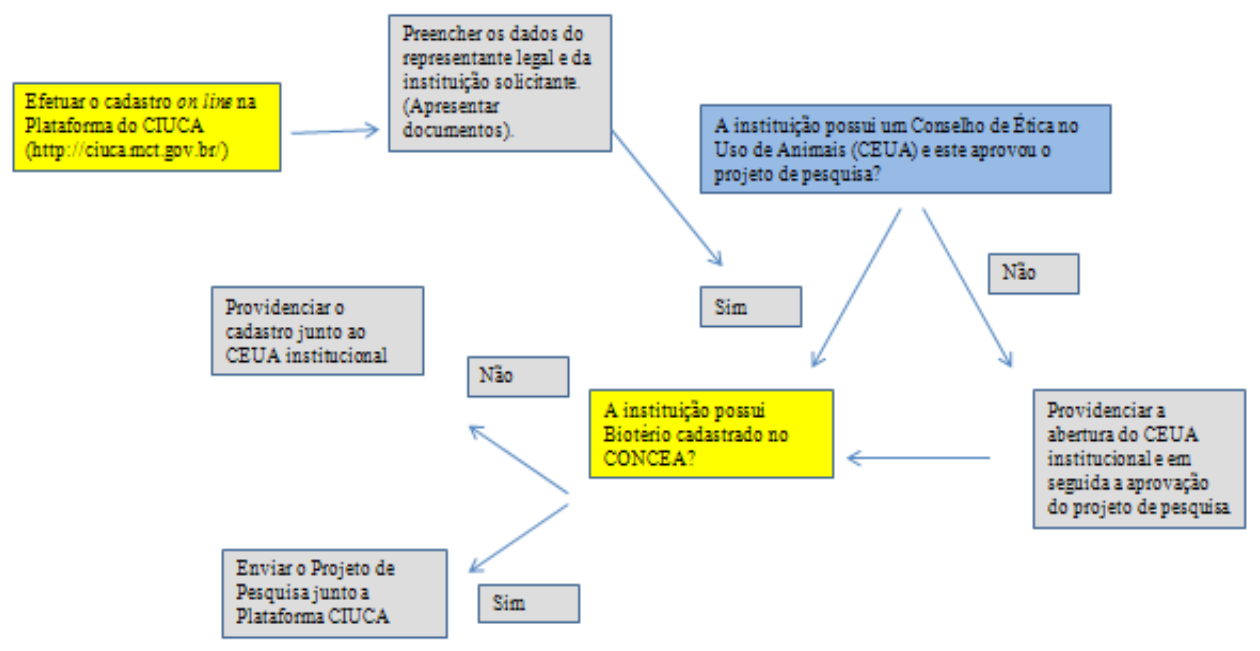

Fonte: adaptada do CIUCA. ${ }^{6}$

\subsection{SOLICITAÇÕES DE ACESSO AO PATRIMÔNIO GENÉTICO E/OU AO CONHECIMENTO TRADICIONAL ASSOCIADO}

A partir da criação do Cgen, outras instituições públicas também foram credenciadas para autorizar os acessos dentro das três diferentes finalidades já apresentadas. Assim, algumas instituições públicas passaram a auxiliar na direção nacional sobre o acesso ao patrimônio genético sem a necessidade de o pesquisador entrar em contato com o Cgen em todos os casos. ${ }^{8,9}$

Todavia, o que era para agilizar o deferimento dos acessos ao descentralizar as autorizações do Cgen acabou por trazer confusões para os pesquisadores de qual órgão recorrer diante da finalidade dos seus acessos. A fim de facilitar o entendimento, a Figura 4 apresenta um esquema da rede de instituições credenciadas ao Cgen e as autorizações concedidas por cada uma delas. 
Figura 4 - Rede de instituições credenciadas ao Cgen e as autorizações concedidas por cada uma delas

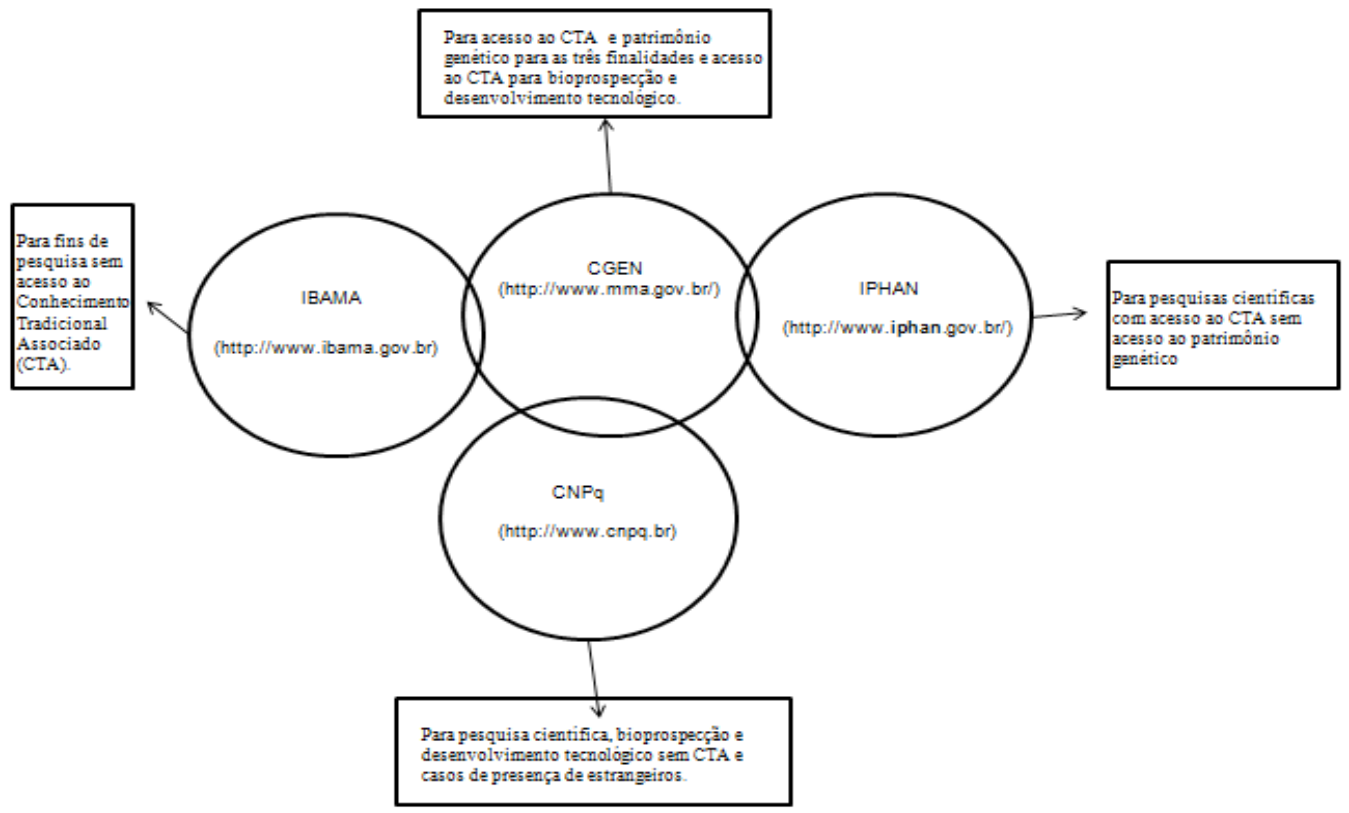

Fonte: adaptada do Conselho de Gestão do Patrimônio Genético. ${ }^{13}$

\subsection{SOLICITAÇÕES AO IBAMA}

Conforme mencionado, o Instituto Brasileiro do Meio Ambiente e dos Recursos Naturais Renováveis (Ibama) foi designado como um dos responsáveis pela emissão de autorizações de acesso e remessa de componente do patrimônio genético para atividades de pesquisa nas áreas biológicas e afins para a coleta sem acesso ao Conhecimento Tradicional Associado com pretensão de bioprospecção. ${ }^{10}$

A documentação a ser apresentada ao Ibama consiste de uma série de formulários e declarações capazes de comprovar a finalidade da pesquisa e seu enquadramento por meio da solicitação ao Instituto. A começar por um Formulário para a Solicitação de Autorização de Acesso e de Remessa de Amostra de Componente do Patrimônio Genético para a Pesquisa Científica, visto que este pode ser o especial, caso o pesquisador deseje incluir projetos no seu portfólio a fim de evitar o envio de documentação apresentada em outros processos. Nesse Formulário está incluso o Termo de Compromisso que deverá ser assinado pelo representante legal da instituição, seguido por uma documentação que comprove que o representante legal possui competência para responder em nome da instituição perante o Poder Público. ${ }^{10}$

Visto que, caso os pesquisadores optem em utilizar o Formulário para a Solicitação de Autorização Especial de Acesso e de Remessa de Amostra de Componente do Patrimônio Genético para a Pesquisa Científica, deve-se constar dentro da proposta de apresentação do projeto de pesquisa o portfólio dos projetos desenvolvidos pela instituição. ${ }^{10}$

Além deste, é preciso um comprovante de que a instituição requerente foi constituída sob as leis brasileiras, o qual pode ser da lei, decreto ou ata de criação da instituição, além de outro comprovante de que a Instituição exerce atividades de pesquisa e desenvolvimento nas áreas biológicas e afins. ${ }^{10}$ 
Esses comprovantes ainda são seguidos de um documento que comprove a qualificação técnica por parte dos pesquisadores para o desempenho de atividades de acesso e remessa de amostra de componente do patrimônio genético. Esse documento pode ser os currículos dos pesquisadores vinculados à pesquisa pela Plataforma Lattes, a qual pode ser acessada no site CNPq, acompanhado da apresentação do projeto de pesquisa. ${ }^{11}$

Para solicitações de um projeto de pesquisa que já envolveu, em um primeiro momento, uma coleta de material biológico, deverá ser apresentada a autorização ou licença dessa coleta prévia ou a indicação da origem do material biológico a ser utilizado para acessar o patrimônio genético. $\mathrm{O}$ pesquisador deverá informar também qual será o destino dos componentes do patrimônio genético nos casos de deferimento. E, por fim, o comprovante de depósito de subamostra de componente do patrimônio genético. A subamostra do patrimônio genético acessado deverá ser depositada em uma instituição brasileira credenciada pelo Cgen como "fiel depositária". ${ }^{10}$

Mesmo após todos esses tramites, ano a ano a instituição que tenha o acesso ao patrimônio genético por meio do Ibama ainda deverá enviar o Relatório de atividades contendo:

a) informações detalhadas sobre o andamento do projeto, ou dos projetos, e atividades integrantes do portifólio, no caso da autorização especial;

b) a indicação das áreas onde foram realizadas as coletas, por meio de coordenadas geográficas;

c) uma listagem quantitativa e qualitativa das espécies ou morfotipos coletados em cada área;

d) a comprovação do depósito das subamostras em instituição fiel depositária credenciada pelo Cgen;

e) apresentação dos termos de transferência de material;

f) a indicação das fontes de financiamento, dos respectivos montantes e das responsabilidades e direitos de cada parte;

g) os resultados preliminares. ${ }^{10}$

\subsection{SOLICITAÇÕES AO CNPQ}

O Conselho Nacional de Desenvolvimento Científico e Tecnológico (CNPq) foi credenciado pelo Cgen para autorizar o acesso à amostra de componente do patrimônio genético para as três finalidades do acesso ao patrimônio genético: pesquisa científica, bioprospecção e desenvolvimento tecnológico. ${ }^{13}$

As autorizações do $\mathrm{CNPq}$ são concedidas às instituições que realizam pesquisas nas áreas biológicas e afins mediante a apresentação de projeto de pesquisa que descreva as atividades de acesso às amostras de componentes do patrimônio genético. O projeto deve ser coordenado por um pesquisador com experiência no assunto e ter financiamento prévio para a sua execução. ${ }^{11}$

Para solicitar o acesso ao patrimônio genético tanto o coordenador do projeto solicitante quando a instituição de vínculo do coordenador devem possuir alguns requisitos. Os coordenadores, além de ter seu currículo cadastrado e atualizado na Plataforma Lattes e ter vínculo formal com a 
instituição que solicitará a autorização, devem ser brasileiros ou estrangeiros em situação regular no país, ter experiência em ensino ou pesquisa nas áreas biológicas e afins, e ter ao menos curso superior ou deter notório saber no tema. ${ }^{11}$

$\mathrm{O}$ envio da documentação à Plataforma Carlos Chagas, portal vinculado ao CNPq para recebimentos dos formulários, por meios eletrônicos deverá ser submetido pelo representante legal da instituição solicitante, sendo este o dirigente máximo ou aquele que tenha uma delegação expressa para responder em nome da instituição perante o Poder Público, pois essa solicitação tem caráter institucional. ${ }^{11}$

A instituição de vínculo do coordenador do projeto deve ser constituída sob as leis brasileiras, executar atividades de pesquisa e desenvolvimento nas áreas biológicas e afins, ter qualificação técnica e estrutura para o manuseio de amostra de componente do patrimônio genético e estar cadastrada no CNPq como executora de Pesquisa e Desenvolvimento (P\&D) nas áreas Biológicas e relacionadas. ${ }^{11}$

Para solicitar a autorização, os pesquisadores que coordenarão os projetos deverão preencher um formulário on-line específico, disponível na Plataforma Carlos Chagas, visto que a Plataforma dispõe de dois formulários: pesquisa científica e bioprospecção/desenvolvimento tecnológico. ${ }^{11}$

Os formulários são divididos em módulos para preencher gradualmente as informações sobre o projeto. O primeiro módulo é sobre o coordenador do projeto e exige o nome e o CPF deste, o segundo é o relacionado ao representante legal, com informações sobre a situação da instituição com o cadastro no $\mathrm{CNPq}$, seguido pelos membros da equipe, os quais podem ser o coordenador, que já foi informado, o vice-coordenador pesquisador, colaboradores, consultores, bolsistas e técnicos.

O terceiro módulo do projeto visa informar o cronograma programático do projeto, o quarto, os dados da instituição, podendo informar também as instituições estrangeiras, seguido pelos anexos que deverão contemplar o projeto de pesquisa; as informações complementares. Posteriormente, temse sobre a fiel depositária seguida pelas fontes de financiamento e a declaração.

Após o encaminhamento dos formulários, espera-se que apareça a mensagem de que o envio foi realizado com sucesso e a opção para a visualização do recibo com as informações. Após o envio, a solicitação poderá ser acompanhada pela Plataforma Carlos Chagas na opção Propostas e Pedidos Submetidos.

\subsection{SOLICITAÇÕES AO IPHAN}

Caso as pesquisas científicas necessitem de autorização de acesso ao Conhecimento Tradicional Associado a um Patrimônio genético, ela será concedida pelo Instituto do Patrimônio Histórico e Artístico Nacional (IPHAN). ${ }^{12}$

Do mesmo modo que as solicitações ao Ibama, ao CNPq e ao Cgen, as autorizações de acesso ao CTA via IPHAN somente poderão ser solicitadas por pessoa jurídica, pública ou privada, constituída pelas leis brasileiras, que exerça atividades de pesquisa nas áreas Biológicas e afins, pois 
essas leis foram regulamentadas pela Medida Provisória n. 2.186-16, de 23 de agosto de 2001 e pelo Decreto n. 3.945, de 28 de setembro de 2001. O comprovante de legitimidade do representante legal da instituição solicitante deverá estar atualizado e autenticado. ${ }^{9}$

As instruções gerais para o acesso ao IPHAN se diferenciam das emitidas pelo Ibama e pelo CNPq pelo fato de o Formulário de Solicitação de Autorização de Acesso ser enviado via caixa postal, preferencialmente com aviso de recebimento e com o diferencial de que as pesquisas podem necessitar de autorizações prévias da Fundação Nacional do Índio (Funai), com validade restrita à obtenção do Termo de Anuência Prévia (TAP) e do Sistema de Autorização e Informação em Biodiversidade à distância (Sisbio) em casos de pesquisa em unidades de cavernas e outras unidades de conservação federal, e ao respectivo Órgão Estadual de Meio Ambiente em caso de conservação Estadual. Quanto ao acesso ocorrer em águas jurisdicionais brasileiras, na plataforma continental e na zona econômica exclusiva, é necessária autorização prévia do Ministério da Defesa - Comando da Marinha.12

Os documentos e formulários necessários para solicitar o acesso ao IPHAN consistem de um Formulário de Acesso contendo o Termo de Compromisso, o qual deve ser assinado pelo representante legal da instituição se comprometendo a acessar o conhecimento tradicional associado apenas para a finalidade autorizada, além do projeto de pesquisa. Em caso de projetos desenvolvidos por mais de uma instituição em forma de cooperação, estes devem ter seus respectivos contratos ou termos de cooperação relacionados à pesquisa científica encaminhada.

A anuência prévia do povo indígena ou da comunidade local envolvida, conforme o caso, acompanhada do relatório que explicite os procedimentos adotados para a sua obtenção também deverão ser encaminhados. Essa comprovação pode ser apresentada na forma de vídeo ou por outros meios idôneos que comprovem o atendimento pleno dos requisitos instituídos pelo Decreto n. 3.945, de 28 de setembro de 2001 e pela Resolução Cgen n. 5, de 26 de junho de 2003. ${ }^{12}$

\subsection{SOLICITAÇÕES AO CGEN}

Em regra geral, todas as solicitações que não se enquadram nas competências aprovadas pelo Ibama, CNPq e IPHAN deverão ser enviada ao Cgen, sendo estas:

a) acesso ao Patrimônio Genético com acesso ao Conhecimento Tradicional Associado para qualquer finalidade com perspectivas econômicas;

b) acesso ao Conhecimento Tradicional Associado para fins de bioprospecção e/ou desenvolvimento tecnológico.

Caso o solicitante encaminhe uma solicitação de competência de outra instituição para o Cgen, esta será encaminhada ao órgão responsável, porém, o tempo gasto para concluir a análise será aumentado. $^{13}$ 
Para solicitar acesso ao Cgen, o formulário utilizado e os documentos são os mesmos apresentados pelas outras instituições da rede, visto que estes deverão ser enviados via caixa postal para a Secretaria Executiva do Cgen e estão disponíveis on-line. ${ }^{13}$

\subsection{PESQUISAS QUE NÃO NECESSITAM DE AUTORIZAÇÃO}

Vale ressaltar que há pesquisas e atividades científicas que não necessitam de autorização para a sua execução porque não se enquadram no conceito de acesso ao patrimônio genético para as finalidades da MP 2.186-16/01. Fato este que faz com que muitos pesquisadores optem por realizar essas atividades a fim de evitar solicitar o acesso aos órgãos regulamentadores. Dessa forma, segundo a Resolução n. 21 do Cgen, estão dispensadas de autorização.

As pesquisas e atividades constantes na Resolução n. 21 do Cgen (alterada pela Resolução n. 28) são aquelas que buscam avaliar ou elucidar a história evolutiva de uma espécie ou de um grupo taxonômico, além das relações dos seres vivos entre si e com o meio ambiente. Também, a diversidade genética de populações, incluindo os testes de filiação, técnicas de sexagem e análises de cariótipo ou de DNA que visam à identificação de uma espécie ou espécime, somados às pesquisas epidemiológicas, às de identificação de agentes etiológicos, de medições da concentração de substâncias conhecidas e de formação de coleções de DNA, tecidos, germoplasma, sangue ou soro. ${ }^{11}$

Primeiramente, ao se tratar de acesso ao Patrimônio Genético e ao Conhecimento Tradicional Associado em uma pesquisa, é fundamental descobrir se a pesquisa em questão realmente necessita de acesso aos órgãos reguladores. Em caso positivo, o segundo passo é identificar qual o órgão responsável pela autorização, considerando a finalidade da pesquisa pretendida, conforme demonstrado pelo Fluxograma na Figura 5.

Figura 5 - Fluxograma para o acesso ao Patrimônio Genético e ao Conhecimento Tradicional Associado

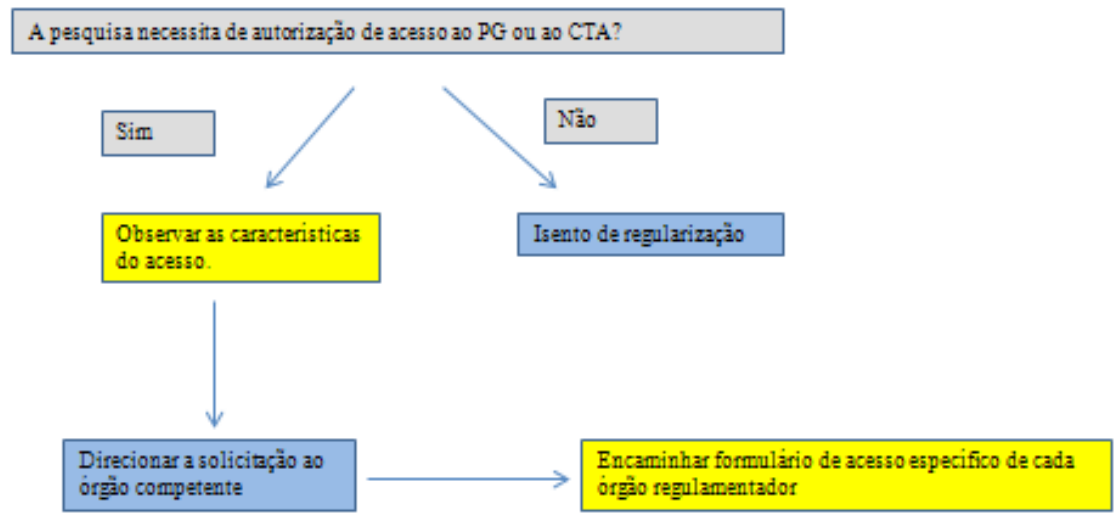

Fonte: adaptada do Conselho de Gestão do Patrimônio Genético. ${ }^{13}$ 


\subsection{SOLICITAÇÕES DE ACESSO À BIODIVERSIDADE VIA IEF}

Para cada finalidade de acesso à biodiversidade em nível estadual existem documentos específicos exigidos pelo Instituto Estadual de Florestas (IEF). Mais especificamente, no âmbito das pesquisas científicas, podem ocorrer solicitações de acesso à biodiversidade dentro ou fora das Unidades de Conservação, com ou sem coleta de amostras e a execução de aulas de campo dentro dessas UCs com ou sem coleta de amostras.

Para solicitar a coleta de amostras tanto durante aulas de campo quanto para pesquisas, o pesquisador deverá apresentar a Carta de Apresentação do Projeto encaminhada pelo chefe do departamento da instituição, seguida do Cadastro de Pesquisa/Termo de Compromisso, do Projeto de Pesquisa com Cronograma de Atividades (incluindo trabalho de campo) e da Carta de Aceite da Instituição Depositária (Herbário, Museu, Coleção, etc.), quando for o caso. Esses documentos a serem apresentados possuem modelos pré-elaborados disponíveis no site do IEF. Desse modo, o pesquisador necessita apenas preencher os campos com as informações do projeto de pesquisa. ${ }^{14}$

Portanto, solicitações com o Instituto Estadual de Florestas do Estado de Minas Gerais são feitas em casos de pesquisas que, diferentemente das enviadas à rede do Cgen, não possuem intuito de bioprospecção, desenvolvidas dentro ou fora de Unidades de Conservação estaduais, com ou sem coleta de material, incluindo a execução de aulas práticas, conforme demonstrado pelo Fluxograma da Figura 6. Entretanto, questões relativas à visita propriamente dita são negociadas diretamente com os responsáveis da Unidade de Conservação em questão.

Figura 6 - Fluxograma para o acesso às Unidades de Conservação (UCs) em nível estadual regularizada pelo IEF

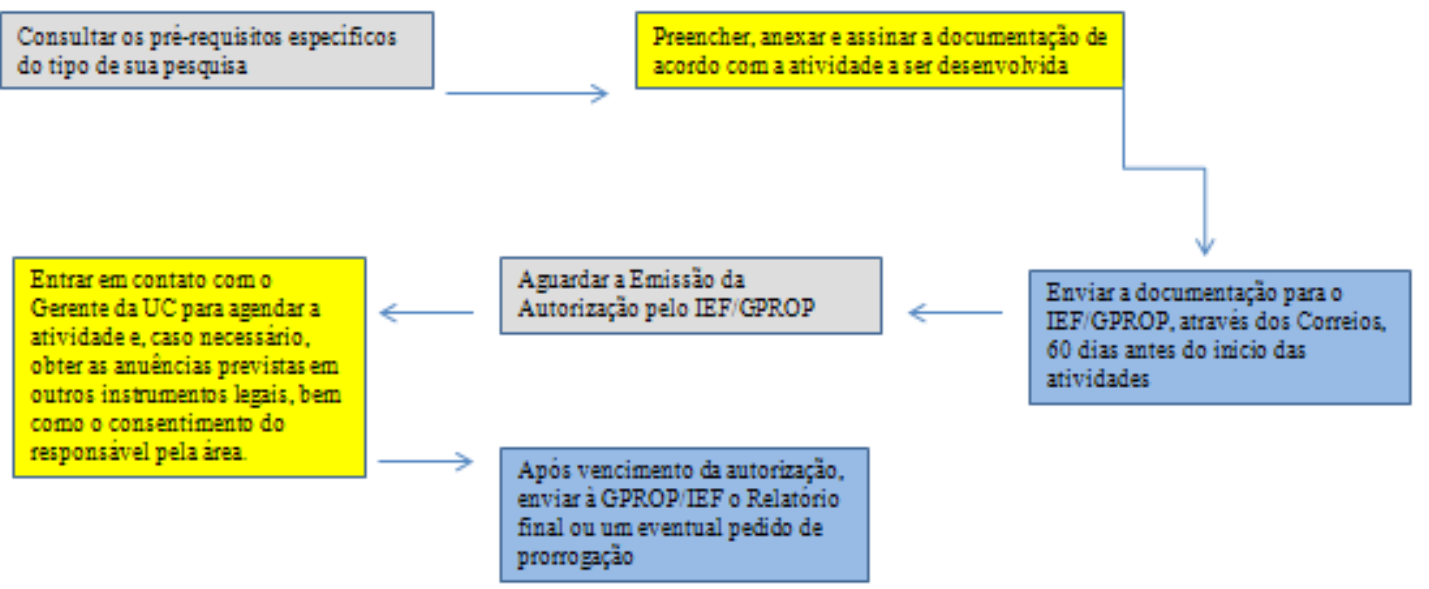

Fonte: adaptada do Instituto Estadual de Florestas. ${ }^{14}$

Portanto, a proteção à biodiversidade inclui acessos de pessoas dentro das Unidades de Conservação, incluindo o caso de aulas práticas com ou sem coleta de amostras. Porém, nos casos de aulas de campo sem coleta de material biológico o pesquisador deve preencher o Cadastro de Visita Técnica/Aula de Campo e encaminhar ao IEF. Cabe ao coordenador do projeto exigir que as normas 
internas das UCs sejam respeitadas, como também apresentar a autorização impressa durante a visita às UCs com os documentos de identidade do grupo presente. Em caso de haver outras questões relativas à aula de campo, estas devem ser tratadas diretamente com o gerente da UC. ${ }^{14}$

\subsection{PROCEDIMENTOS PARA A SOLICITAÇÃO DE PATENTES COM O INPI}

O Instituto Nacional da Propriedade Industrial (INPI), criado em 1970, é um órgão que concede patentes dentro do território nacional brasileiro. Ele está vinculado ao Ministério do Desenvolvimento, Indústria e Comércio Exterior (MDIC), é uma autarquia federal e tem como responsabilidade o aperfeiçoamento, a disseminação e a gestão do sistema brasileiro de concessão e garantia de direitos de propriedade intelectual para a indústria. ${ }^{15}$

Por isso, os serviços prestados pelo INPI são os registros de marcas, desenhos industriais, indicações geográficas, programas de computador e topografias de circuitos, concessões de patentes e averbações de contratos de franquia e as distintas modalidades de transferência de tecnologia. ${ }^{16}$

As patentes podem ser solicitadas por pessoa física ou jurídica ao representarem uma solicitação por meio de uma instituição. Porém, nos dois casos, os documentos necessários para o depósito da patente são:

a) requerimento: consiste da apresentação de um Pedido de Patente ou Certificado de Adição;

b) relatório descritivo: deve descrever a invenção ou o modelo de utilidade clara e precisamente, de forma a ser reproduzível por um técnico no assunto. Também deve apontar o problema existente e a solução proposta, ressaltando a novidade, o efeito técnico alcançável e as vantagens em relação ao estado da técnica;

c) reivindicações: devem definir e delimitar o direito do autor do pedido e, por isso, devem ser fundamentadas no relatório descritivo, caracterizando as particularidades do pedido de forma clara sem ambiguidades;

d) desenhos (se for o caso): as figuras e desenhos como gráficos, esquemas, fluxogramas, etc. devem auxiliar na compreensão de uma invenção e podem ser necessários para o entendimento de um produto totalmente inovador, por exemplo;

e) listagem de Sequência Biológica, em meio eletrônico (se for o caso): necessária para pedidos de patente que contêm a descrição de uma sequência de nucleotídeos ou aminoácidos. Neste item, todas as sequências ou partes de sequências devem ser descritas no pedido e distinguidas por meio de um número de identificador;

f) resumo: consiste em uma descrição sucinta da matéria exposta no pedido. Deve compreender de 50 a 200 palavras, não excedendo 20 linhas de texto e não deve haver citação ao mérito ou valor da invenção ou modelo de utilidade;

g) comprovante de pagamento original da retribuição relativa ao depósito: deve ser enviado em forma de anexo. ${ }^{17}$ 
O envio desses documentos antes acontecia por meio de caixa postal ou entregues diretamente ao INPI, porém, recentemente, o site criou a plataforma e-Patentes, que representa um amplo conjunto de soluções as quais visam à modernização do processamento das patentes dentro do Instituto Nacional da Propriedade Industrial no qual pode ser feito o depósito de forma on-line. ${ }^{17}$

Os formulários referentes ao depósito de um pedido de patente ou certificado de adição de invenção devem ser apresentados ao INPI em três vias. Os demais devem ser apresentados em duas vias. Em todos os casos, o INPI devolve ao depositante uma das vias como comprovante após a protocolização. ${ }^{17}$

Para validar as petições, os respectivos formulários devem ser corretamente preenchidos e assinados com o assunto ao qual a petição se refere no campo correspondente, como também com o número de folhas utilizadas na petição. Em anexo, deve constar a Guia de Recolhimento da União (GRU), que é o comprovante de pagamento da taxa referente ao serviço requerido, além dos documentos cabíveis em cada caso. ${ }^{17}$

Ao depositar um pedido de patente que engloba o envio dos documentos já citados, o solicitante recebe um número de protocolo para acompanhar a tramitação do envio. De acordo com o INPI, o depósito do pedido de patente tem como prazo de análise aproximadamente 60 dias. ${ }^{17}$

O solicitante da patente deverá requerer um exame técnico em até 36 meses contados a partir da data de depósito. Esse exame técnico tem como objetivo analisar a patenteabilidade do pedido, a adaptação do pedido à natureza reivindicada, entre outras exigências técnicas. Concluído o exame, será proferida a decisão deferindo ou indeferindo o pedido de patente. ${ }^{17}$

Os trâmites processuais de um pedido de patente envolvem uma sequência de prazos e entrega de documentos. Para mais esclarecimentos, nos Fluxogramas das Figuras 7, 8 e 9 consta o artigo da Lei n. 9.279/96, que referencia a parte do processo em questão, além da descrição dos prazos previstos.

Figura 7 - Fluxograma da tramitação do pedido de patente parte 1

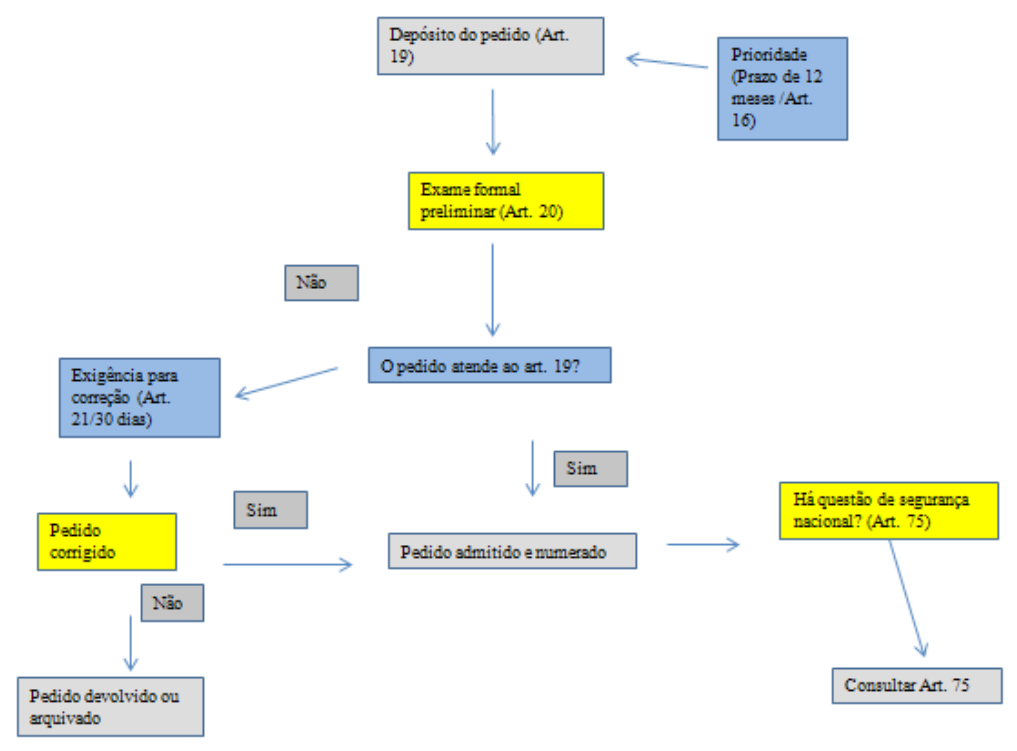

Fonte: adaptada do Instituto Nacional da Propriedade Industrial. ${ }^{17}$ 
Figura 8 - Fluxograma da tramitação do pedido de patente parte 2

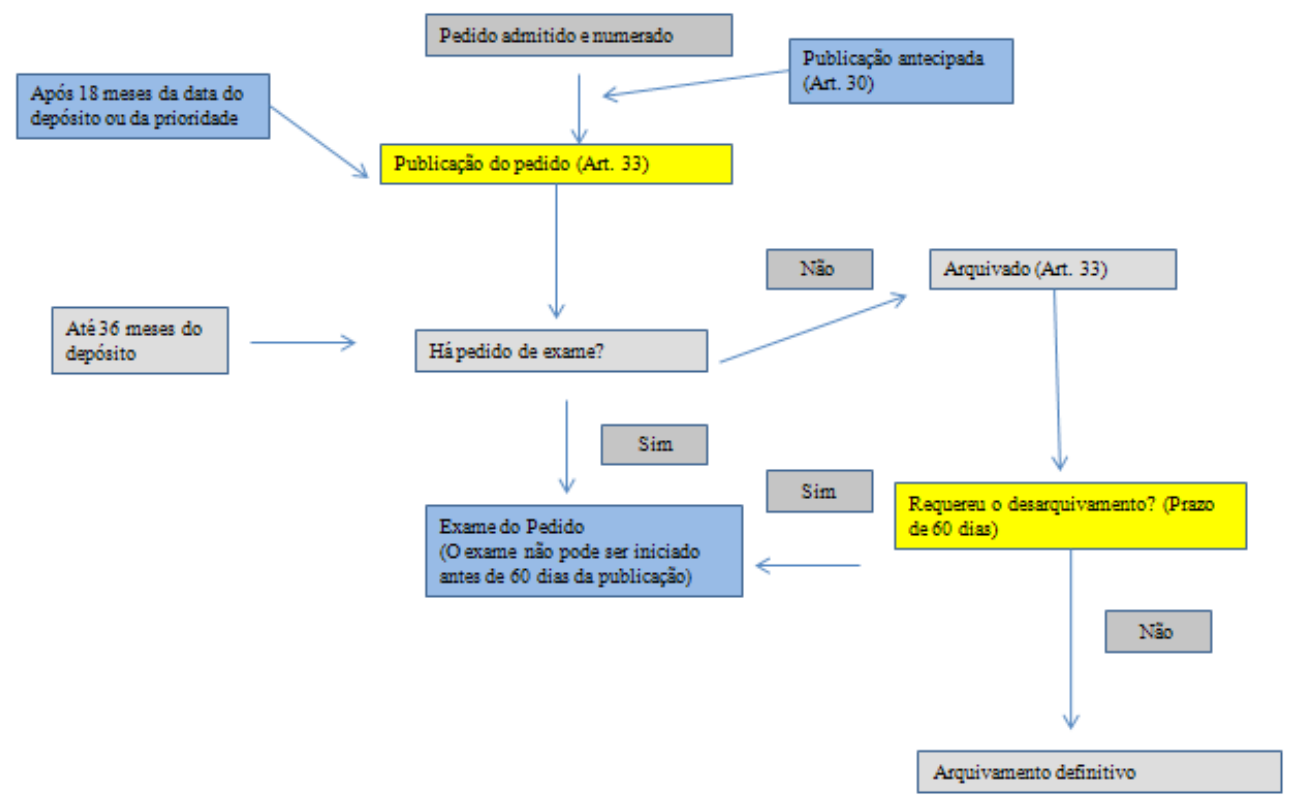

Fonte: adaptada do Instituto Nacional da Propriedade Industrial. ${ }^{17}$

Figura 9 - Fluxograma da tramitação do pedido de patente parte 3

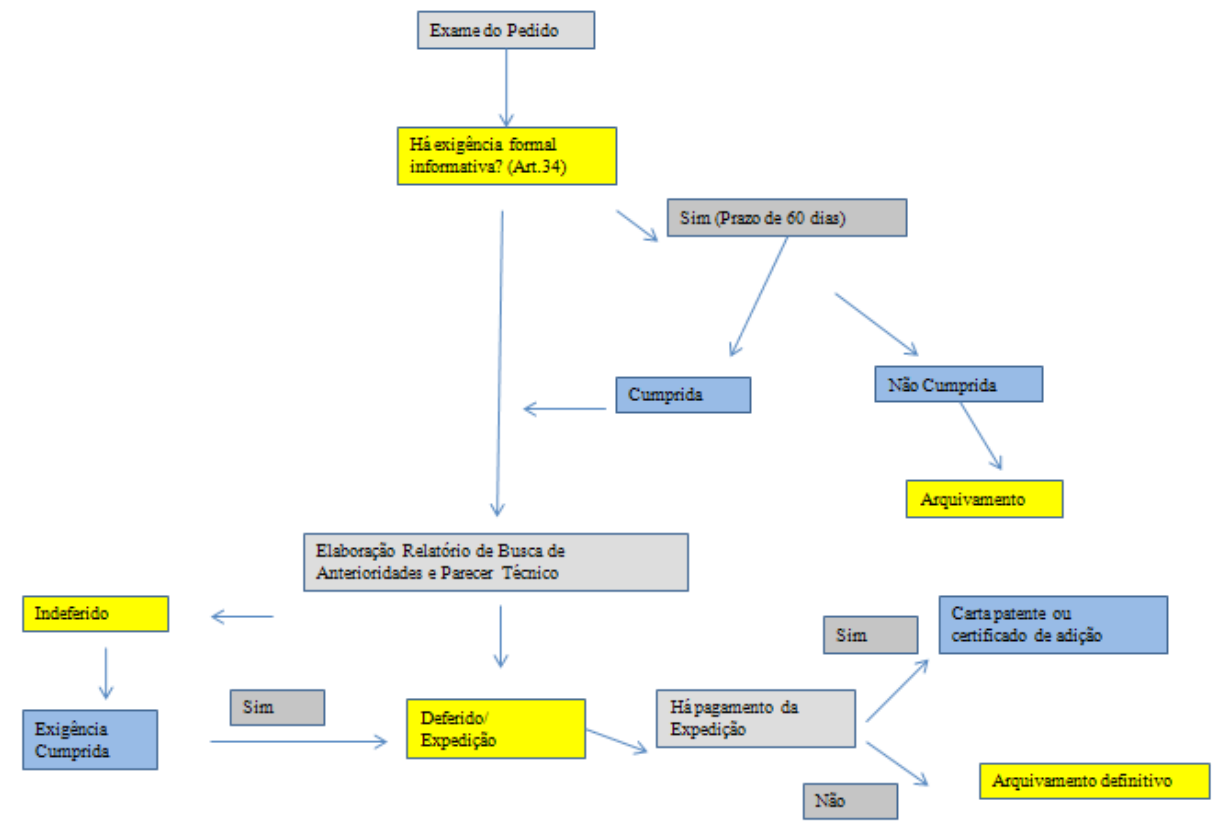

Fonte: adaptada do Instituto Nacional da Propriedade Industrial. ${ }^{17}$

\section{CONCLUSÕES E PERSPECTIVAS}

As pesquisas em biotecnologia na prática estão relacionadas a excessos de prazos, formulários e autorizações múltiplas e, com isso, têm-se reflexos negativos. Um exemplo está no relato de que todos os anos inúmeros novos estudos internacionais são interrompidos. Essas diversas autorizações acontecem no caso das pesquisas clínicas para lançamento de novos medicamentos, pois estas 
necessitam de aprovação primeiramente de um Conselho de Ética no Uso de Animais (CEUA) na fase de pesquisa, seguida por uma do Comitê de Ética em Pesquisa para Seres Humanos (CEPS) e, em certos casos, outra da Comissão Nacional de Ética em Pesquisa (Conep), além da avaliação da Agência Nacional de Vigilância Sanitária (Anvisa).

Portanto, para fazer pesquisas no Brasil, mesmo diante da biodiversidade, melhor que seja um cientista brasileiro que já compartilha dessa cultura de imobilidade administrativa, ao passo que em uma visão estrangeira tal morosidade pode vir a ser mais mal compreendida.

As leis acerca do acesso ao patrimônio genético e ao conhecimento tradicional associado e da proteção à biodiversidade em nível estadual são fundamentais para que o dano com a fauna e a flora, presenciado no Brasil, seja evitado. Como também é fundamental a existência de um Comitê de Ética para a aprovação das pesquisas antes que sejam gerados danos a indivíduos voluntários ou animais envolvidos em projetos de pesquisas.

Porém, a lentidão para a aprovação legal dessas "licenças" concedidas pelo Governo pode vir a atrasar o desenvolvimento tecnológico do país. Somando a falta de recursos e outras questões de infraestrutura física das universidades, que a priori são de foco educacional e não de produção de inovação, tem-se uma problemática que reflete no quantitativo anual das pesquisas produzidas no Brasil.

Ao analisar a rede de instituições responsáveis pela regulamentação do acesso ao Patrimônio Genético e ao Conhecimento Tradicional Associado, observou-se que a divisão da demanda do CGEN, na tentativa de agilizar a liberação das solicitações, acabou por dificultar a compreensão do processo, pois muitas vezes os pesquisadores ficam sem saber a quem solicitar seu pedido diante da necessidade de observar o enquadramento do projeto a ser submetido quanto ao objeto e à finalidade das solicitações para, assim, determinar qual das várias instituições regulamentadores é responsável.

O tempo necessário para se patentear uma invenção no Brasil, por consequência de um baixo número de analistas em relação à demanda, excesso de prazos e formulários exigidos, entre outras questões, chega a ser desmotivante para o pesquisador que busca ter o registro de sua invenção. O reflexo está na colocação do país no ranking mundial de patentes válidas visto que o Brasil está na 19a posição, com 41.453 patentes, e o primeiro colocado, os Estados Unidos, possui 2,2 milhões de patentes.

Faz-se necessário, também, que outros estudos destaquem esse tema para que seja possível alcançar melhorias no excesso de burocracia encontrada durante o processo de produção do conhecimento em biotecnologia.

\section{REFERENCIAS}

1. Agência Brasileira de Desenvolvimento Industrial; Centro de Gestão e Estudos Estratégicos. Panorama da Biotecnologia no Brasil e no Mundo. 2009. [acesso em 2014 jul 15]. Disponível em: http://www.cgee.org.br/repositorio/biblioteca_cgee.html

2. Frasca L. Burocracia barra pesquisa brasileira. Revista do Farmacêutico I. 2010 jan; 1(105):52-53. 
3. Ministério da Saúde. Plataforma Brasil. Brasília: Ministério da Saúde. [Internet]. Aplicação. [acesso em 2014 set 28]. Disponível em: http://aplicacao.saude.gov.br/plataformabrasil/login.jsf

4. Brasil. Lei n. 11.794, de 08 de outubro de 2008. Regulamenta o inciso VII, do $\$ 1$, do art. 225 da Constituição Federal, estabelecendo procedimentos para o uso científico de animais; revoga a Lei n. 6.638/79 e dá outras providências. Diário Oficial da União, Brasília; 2008 out 09.

5. Ministério da Ciência, Tecnologia e Informação. Conselho Nacional de Controle de Experimentação Animal. Brasília, DF: Ministério da Ciência, Tecnologia e Informação. 2012. [acesso em 2014 set 29]. Disponível em: http://www.mct.gov.br/index.php/content/view/310553.html

6. Ministério da Ciência, Tecnologia e Informação. Cadastro das Instituições de Uso Científico de Animais. Brasília: Ministério da Ciência, Tecnologia e Informação, 2013. [acesso em 2014 set 29]. Disponível em: http://ciuca.mct.gov.br/

7. Ministério da Ciência, Tecnologia e Inovação. Orientação Técnica n. 3, de 22 de outubro de 2013. Diário Oficial da União, Brasília; 2013 out 23.

8. Lima GGB. A conservação da fauna e da flora silvestres no Brasil: a questão do tráfico ilegal de plantas e animais silvestres e o desenvolvimento sustentável. Rev. Jur. 2007 ago; 9(86):134-150.

9. Brasil. Medida provisória n. 2.186-16, de 23 de agosto de 2001. Dispõe sobre o acesso ao patrimônio genético, a proteção e o acesso ao conhecimento tradicional associado e dá outras providências. Diário Oficial da República Federativa do Brasil, Brasília; 2001 ago 23.

10. Ibama. Cartilha sobre acesso ao patrimônio genético e remessa de amostra do patrimônio genético. Brasília; 2005. [acesso em 2014 set 17]. Disponível em: http://www.ibama.gov.br/servicos/ acesso-e-remessa-ao-patrimonio-genetico

11. Ministério da Ciência, Tecnologia e Inovação. Conselho Nacional de Desenvolvimento Científico e Tecnológico. Autorização de acesso ao patrimônio genético. Instruções de preenchimento do formulário on-line. [acesso em 2014 set 29]. Disponível em: http://www.cnpq.br/ documents/10157/746c0db2-42fd-4ad3-8769-48f9e4e6fbd8

12. Ministério da Cultura. Instituto de Patrimônio Histórico e Artístico Nacional Brasília: Ministério da Cultura. 2014. Serviços. [acesso em 2014 set 19]. Disponível em: http://portal.iphan.gov.br

13. Ministério do Meio Ambiente. Conselho de Gestão do Patrimônio Genético. Brasília: Ministério do Meio Ambiente. [acesso em 2014 set 29]. Disponível em: http://www.mma.gov.br

14. Instituto Estadual de Florestas. Portal Meio Ambiente. [acesso em 2014 set 30]. Disponível em: www.ief.mg.gov.br

15. Ministério do Desenvolvimento, Indústria e Comércio Exterior. Instituto Nacional da Propriedade Industrial. Brasília: Ministério do Desenvolvimento, Indústria e Comércio Exterior. 2008. [acesso em 2014 out 01]. Disponível em: www.inpi.gov.br 
16. Moreira AC, Antunes MAS, Pereira NJ. Patentes: Extratos de Plantas e derivados. Revista Biotecnologia Ciência e Desenvolvimento. 2004 jul; 1(33):62-71.

17. Instituto Nacional da Propriedade Industrial. Guia de Tramitação de pedidos de patentes 2008. Brasília: Ministério do Desenvolvimento, Indústria e Comércio Exterior. 2008. [acesso em 2014 out 01]. Disponível em: www.inpi.gov.br

Recebido em 18 de fevereiro de 2015 Aceito em 16 de junho de 2015 